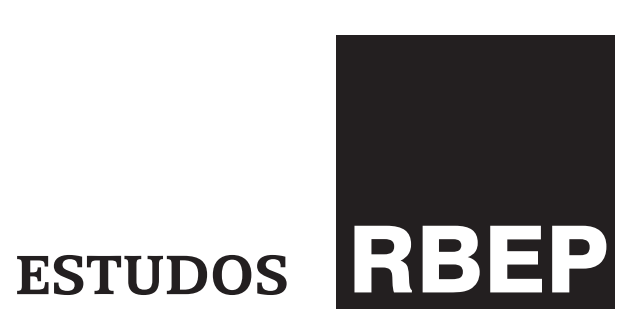

\title{
Relações entre indicadores de qualidade de ensino e desempenho de estudantes dos cursos de Pedagogia do Brasil no Exame Nacional de Desempenho dos Estudantes
}

Leo Lynce Valle de Lacerda

Cássia Ferri

http://dx.doi.org/10.1590/S2176-6681/330512908

\section{Resumo}

Tem como objetivo investigar as relações entre os indicadores presentes no Conceito Preliminar de Curso (CPC) dos cursos de Pedagogia no Brasil, com base nos resultados do Exame Nacional de Desempenho dos Estudantes (Enade) de 2008 para essa área. Sete indicadores foram analisados: percentual de doutores, percentual de mestres, percentual de docentes em regime integral ou parcial, infraestrutura, organização didáticopedagógica, Indicador de Diferença entre os Desempenhos Observado e Esperado (IDD) e nota no Enade. Os resultados, apresentados segundo as combinações de organização acadêmica e categoria administrativa das IES 
brasileiras, mostraram relações significativas dos percentuais de doutores e de mestres com o Enade e o IDD, sendo mais fortes nas universidades estaduais e nas faculdades integradas privadas. O indicador de infraestrutura não se mostrou relevante para a maioria das combinações entre organização acadêmica e categoria administrativa, exceto para universidades estaduais. Os indicadores planos de ensino e dedicação parcial/integral mostraram correlação fraca ou ausente. Concluiu-se que a relação entre os indicadores de qualidade e o desempenho foi dependente da combinação entre organização acadêmica e categoria administrativa, de modo que se sugere que aprimoramentos no CPC poderiam considerar tais diferenças entre as IES. Estudos como este, em outras áreas de conhecimento, forneceriam mais subsídios para aperfeiçoar o Sistema Nacional de Avaliação da Educação Superior (Sinaes) e garantir os princípios nele estabelecidos.

Palavras-chave: políticas educacionais; exames de desempenho; Enade; Pedagogia.

\section{Abstract \\ Relationships between teaching quality indicators and student performance in Brazilian undergraduate courses of Pedagogy in the National Student Performance Exam (Enade)}

The article aims to investigate the relationships between the indicators present in the preliminary course program score (CPC) of the Pedagogy undergraduate courses in Brazil, based on the results of the National Student Performance Exam (Enade) of 2008 for this area. Seven indicators were analyzed: percentage of scholars with doctorate degree, percentage of scholars with master's degree, percentage of professors working full or parttime, infrastructure, didactic and pedagogical organization, the Indicator of Difference between Expected and Observed Performance (IDD) and Enade's grade. The results, presented according combinations of academic organization and administrative category of Brazilian higher education institutions, showed significant connections between the percentage of scholars with doctorate degree and master's degree with the Enade and the IDD, being stronger in the state universities and private colleges. The infrastructure indicator was not relevant for most combinations between academic organization and administrative category, except for state universities. Indicators related to didactic and pedagogical organization and to professors' working hours showed weak or complete lack of correlation. It was concluded that the relationship between quality indicators and performance depended on the combination of academic organization and administrative category. This suggests that improvements in the preliminary course program score should consider such differences amongst 
higher education institutions. Similar studies to this one, approaching other areas of knowledge, would provide more support in order to improve the National Higher Education Assessment System (Sinaes) and ensure the principles therein established.

Keywords: educational policies; performance tests; Enade; Pedagogy.

\section{Introdução}

A implantação do Sistema Nacional da Avaliação da Educação Superior (Sinaes) no Brasil, em 2004, é um divisor de águas no processo de avaliação das instituições de educação superior (IES). O sistema foi estabelecido em cinco princípios fundamentais: 1) a responsabilidade social com a qualidade da educação superior; 2) o reconhecimento da diversidade do sistema; 3) o respeito à identidade, à missão e à história das instituições; 4) a globalidade, isto é, a compreensão de que a instituição deve ser avaliada considerando um conjunto significativo de indicadores de qualidade, vistos em sua relação orgânica e não de forma isolada; e 5) a continuidade do processo avaliativo. O Sinaes propôs uma ousada transformação no processo avaliativo institucional, explicitada nos desafios a que se propôs, conforme citado por Ristoff (2004, p. 179):

[...] seis importantes desafios terão que ser considerados e enfrentados: (1) o deslocamento de centro de avaliação de uma prova para um conjunto diversificado de instrumentos, (2) a integração dos instrumentos de avaliação e de informação e dos processos avaliativos desenvolvidos por diferentes órgãos do Ministério da Educação e dos sistemas estaduais, (3) a valorização dos aspectos qualitativos e interpretativos nos processos e instrumentos, (4) a institucionalização de programas permanentes de capacitação de avaliadores, (5) a criação e consolidação da cultura de autoavaliação nas Instituições de Ensino Superior, e (6) a implantação de processos de meta-avaliação.

Três desses desafios chamam a atenção: o conjunto diverso de instrumentos, a integração e a valorização de aspectos qualitativos. Quando examinada a operacionalização do sistema, o que se nota é um movimento contrário ao que foi originalmente proposto. Devido a isso, o sistema tem sido objeto de críticas contundentes no que se refere ao cumprimento dos propósitos iniciais, que têm se refletido não somente nas IES, mas também no próprio órgão operacionalizador do sistema, o Instituto Nacional de Estudos e Pesquisas Educacionais Anísio Teixeira (Inep). Um dos pontos centrais nessa discussão refere-se ao papel que uma das modalidades previstas no Sinaes tem para a avaliação das IES. Em sua origem, o Sinaes previu três modalidades de avaliação:

- A avaliação das IES (Avalies), realizada por atores internos das IES sob a coordenação da Comissão Própria de Avaliação (CPA). 
A autoavaliação integra dez dimensões que abrangem desde os documentos norteadores da instituição até a sustentabilidade financeira. Essa avaliação tem como produto final o relatório de autoavaliação, que é reeditado a cada dois anos.

- A Avaliação dos Cursos de Graduação (ACG), realizada pelos avaliadores do Banco de Avaliadores do Sistema Nacional de Avaliação da Educação Superior (Basis), por meio de um instrumento específico de avaliação composto por indicadores em escala ordinal agrupados em três dimensões - corpo social, infraestrutura e organização didático-pedagógica - e utilizado para regulação dos atos de autorização, reconhecimento e renovação de reconhecimento dos cursos de graduação.

- A avaliação do desempenho dos estudantes dos cursos de graduação por meio de provas de formação geral e específica que compõem o Exame Nacional de Desempenho dos Estudantes (Enade).

Dessas modalidades, o Enade tem sido a fonte predominante de indicadores para o processo regulatório, culminando no disposto pela Portaria Normativa MEC no 4/2008 que estabeleceu a dispensa de avaliação in loco para os cursos que obtiverem Conceito Preliminar de Curso (CPC) - um dos indicadores derivados, em parte, do Enade - acima de 3 (Brasil. MEC, 2008). Nessa composição, são utilizados como insumos a nota final dos ingressantes e dos concluintes e o Indicador de Diferença entre os Desempenhos Observado e Esperado (IDD). Desde 2011, os ingressantes de cursos superiores deixaram de realizar as provas do Enade e, em substituição, o Inep, em 2012, propôs a utilização dos resultados do Enem desses estudantes como variável para a composição desse índice.

Apesar do uso para a regulação, desde o primeiro resultado do Enade detectaram-se limitações neste exame. Vendramini (2005, p. 40) destacou a não comparabilidade de resultados no exame, "diante das limitações de análise e de inferências sobre o desempenho dos estudantes e cursos obtidos no Enade" e propôs modelos multidimensionais baseados na teoria de resposta ao item, atualmente cogitados na formulação do exame.

Paralelamente a esse contexto da avaliação do desempenho dos estudantes, a regulação dos cursos de graduação prevê a obrigatoriedade (disposta na Lei de Diretrizes e Bases da Educação Nacional) de um corpo docente com titulação e regime de trabalho adequado à formação universitária. Esses indicadores, somados a aspectos relacionados à infraestrutura e à organização didático-pedagógica dos cursos, que constam nos instrumentos de avaliação do Inep são utilizados para a composição do CPC e do Índice Geral de Cursos (IGC), um índice geral para a instituição. Esses cinco indicadores - percentual de mestres, percentual de doutores, percentual de docentes com dedicação parcial/ integral, infraestrutura e organização didático-pedagógica, os dois últimos representados pelas respostas positivas em uma determinada questão do questionário socioeconômico respondido pelos alunos que prestam o Enade - são insumos para a construção do CPC e, consequentemente, do 
IGC (que agrega a avaliação dos programas stricto sensu realizada pela Coordenação de Aperfeiçoamento de Pessoal de Nível Superior - Capes). O exame do novo algoritmo de cálculo do CPC, proposto pela Nota Técnica $n^{o}$ 29, de outubro de 2012 (Brasil. Inep, 2012), nos informa o peso que o Enade tem nesse índice:

$$
\begin{gathered}
\mathrm{CPC}=(0,15 * \mathrm{NPD})+(0,075 * \mathrm{NPM})+(0,075 * \mathrm{NPR})+(0,075 * \mathrm{NF}) \\
+(0,075 * \mathrm{NO})+(0,35 * \mathrm{NIDD})+(0,20 * N C)
\end{gathered}
$$

Dos insumos utilizados para o cálculo, NPD, NPM e $\mathrm{NPR}^{1}$ se referem aos percentuais de doutores, de mestres e de docentes em regime de tempo integral ou parcial, provenientes do Censo da Educação Superior. As notas referentes à infraestrutura (NF) e organização didático-pedagógica são obtidas no questionário socioeconômico preenchido pelo estudante que presta o Enade. A nota do indicador de diferença entre os desempenhos observado e esperado (Nidd) é obtida a partir do desempenho no Enem dos estudantes ingressantes inscritos no Enade; e a nota do concluinte (NC) é obtida a partir das médias gerais dos concluintes do Enade. Percebe-se que dos sete indicadores utilizados para o CPC três não são retirados do Enade: os percentuais de mestres, de doutores e de docentes com dedicação parcial/integral. Estes perfazem 30\% dos pesos do CPC ao passo que os 70\% restantes são extraídos do exame de desempenho. Esses percentuais não se modificaram no novo cálculo do CPC em relação àquele que vinha sendo utilizado até 2011.

Essa ênfase dada ao desempenho dos estudantes na avaliação geral da instituição tem sido amplamente discutida. Weber (2010, p. 1264) destacou o caráter reducionista do sistema ao utilizar os resultados do Enade:

\footnotetext{
A ênfase dada à variável "desempenho do estudante", nos resultados obtidos pelas IES, finda por transformar a proposta do Sinaes de avaliação como processo formativo em simples avaliação de resultados, com privilegiamento, portanto, da tônica tecnológica, segundo a concepção de House.
}

A avaliação da infraestrutura e da organização didático-pedagógica, obtida pelas notas dadas pelos alunos, é considerada por Rothen e Barreyros (2011, p. 31) uma das limitações do algoritmo, tendo em vista que nessa prática reside a ideia de que "a avaliação discente é suficiente, contrariando a prática do Ministério de conduzir a avaliação dos insumos por especialistas das áreas ou de avaliação".

Mesmo o uso dos percentuais de doutores e docentes em regime de tempo parcial/integral é criticado. Bittencourt, Casartelli e Rodrigues (2009, p. 679) mostram que o requisito de $1 / 3$ de doutores não tem efeito real sobre a pontuação da IES privada, "especialmente devido aos altos índices de doutores nas universidades federais. O mesmo ocorre em relação a professores em regime de tempo integral". Trabalhos como o de Embiruçu, Fontes e Almeida (2010) propõem uma métrica mais completa para a avaliação do desempenho docente, que utiliza indicadores de ensino, pesquisa e extensão, como suporte à avaliação das instituições, complementando variáveis como titulação e regime de trabalho. 
Apesar dos inúmeros debates acerca da adequação do sistema, sua operacionalização tem provocado mudanças diretas no cotidiano das IES, especificamente nos cursos de Pedagogia, visto que o CPC foi (e tem sido) utilizado para a regulação do oferecimento de vagas para a área (em 2009, algumas instituições tiveram negada a possibilidade de oferecer novas vagas em decorrência da insuficiência de seus conceitos de curso).

Tais discussões e fatos justificam a preocupação da comunidade acadêmica envolvida com a avaliação acerca da utilização de índices de aferição da qualidade da educação superior brasileira promovida pelo Sinaes. Apesar dessa preocupação, poucos foram os estudos relacionados a esses índices nos cursos de graduação brasileiros. Destes, pode-se destacar o trabalho de Gurgel (2010) nas áreas de ciências agrárias e saúde e de Bordas et al. (2008) na área de Pedagogia. Diante desse contexto, torna-se de interesse para as discussões uma análise das relações encontradas entre os indicadores de qualidade e desempenho, publicados pelo Inep, para as IES brasileiras, em especial, na área de Pedagogia, como propõe este estudo, tendo em vista a relação dessa área com a formação de professores para a educação básica. Por meio desse exame, pretende-se investigar o quão relevante tem sido a aferição de indicadores, como os percentuais de mestres e de doutores, de docentes em regime parcial e integral, e a opinião dos alunos acerca dos planos de ensino e equipamentos para aulas práticas, como forma de indicação da qualidade do ensino nos cursos de Pedagogia do Brasil.

\section{O CPC decomposto publicado pelo Inep e as condições metodológicas deste estudo}

Este estudo teve como base de dados a planilha de Conceito Preliminar de Curso (CPC) disponibilizada publicamente no site do Inep, relativa ao ano de 2008, em que os cursos de Pedagogia foram avaliados. Houve necessidade de um tratamento de dados previamente ao estudo propriamente dito. Dos cursos de Pedagogia constantes na planilha "CPC decomposto" foram eliminados aqueles que não apresentaram algum dos indicadores de estudo ou que apresentaram CPC sem conceito. Dos 1.176 registros constantes na planilha para a área de Pedagogia, restaram 744 registros que apresentavam todos os indicadores escolhidos para o estudo, quais sejam:

- O percentual de respostas satisfatórias à pergunta referente à infraestrutura (\%Eq). ${ }^{2}$ A pergunta do questionário do Enade sobre infraestrutura é a seguinte: "Aulas práticas: os equipamentos disponíveis são suficientes para todos os alunos?"3

- O percentual de respostas satisfatórias à pergunta referente aos planos de ensino (\%PE). A pergunta do questionário do Enade sobre a organização didático-pedagógica é a seguinte: "Os planos de ensino contêm todos os seguintes aspectos: objetivos; procedimentos

\footnotetext{
${ }^{2}$ Transcreve-se aqui literalmente o que prescrevia a nota técnica do Inep que tratava do CPC referente ao Enade 2008. Essa mesma transcrição foi realizada para o indicador relativo aos planos de ensino. Notar que para o resultado do Enade de 2011 o cálculo das notas destes dois indicadores foi modificado, passando-se a utilizar pesos para cada alternativa de cada uma das questões.

${ }^{3}$ As alternativas de resposta são: $(\mathrm{A})=$ Sim, em todas elas. / (B) $=$ Sim, na maior parte delas. / $(\mathrm{C})=$ Sim, mas apenas na metade delas. / (D) = Sim, mas em menos da metade delas. / (E) = Não, em nenhuma. A partir desta pergunta, considerou-se que avaliaram positivamente a infraestrutura os alunos que responderam (A) ou (B).
} 
de ensino e avaliação; conteúdos e bibliografia da disciplina?" . ${ }^{4}$ A partir desta pergunta, considerou-se que avaliaram positivamente a organização didático-pedagógica os alunos que responderam que todos os planos de ensino contém esses aspectos.

- O percentual de mestres (\%Ms), cuja informação é retirada diretamente do Censo da Educação Superior.

- O percentual de doutores (\%Dr), provindo do Censo da Educação Superior.

- O percentual de docentes com regime de dedicação integral ou parcial (\%DI). Essa informação também é extraída do Censo da Educação Superior.

- O Enade contínuo (Enac), utilizado aqui ao invés da faixa Enade que caracteriza o conceito. Este valor é padronizado para uma escala que varia de zero a cinco.

- O Indicador da Diferença entre os Desempenhos Observado e Esperado ou IDD contínuo (IDDc), padronizado da mesma forma que o Enade contínuo.

Tendo em vista que nos indicadores \%Eq, \%PE, \%Ms, \%Dr e \%DI é atribuída nota zero ${ }^{5}$ quando a informação coletada nas bases utilizadas pelo Inep não indica valor, optou-se pela não utilização dos registros em que esses indicadores apresentaram valor zero. Dessa forma, o número final de registros utilizado foi reduzido para 472 .

O exame das correlações entre os indicadores utilizados neste estudo foi realizado em dois níveis: no primeiro, foram testadas as correlações para o Brasil sem distinção da organização acadêmica ou categoria administrativa. No segundo, distinguiram-se as seguintes combinações entre a organização acadêmica e a categoria administrativa da IES: universidade federal; universidade estadual; universidade privada; faculdade privada; centro universitário privado; faculdade integrada privada; e instituto ou escola superior privada. As combinações que apresentaram número de IES inferior a dez (cinco universidades municipais, três faculdades municipais e quatro faculdades estaduais) não foram incluídas nos resultados das combinações, apesar de participarem do cálculo geral das correlações para o Brasil.

Para as análises, foi utilizada a correlação de postos de Spearman. Esse índice propõe quantificar a relação entre duas variáveis por meio dos postos dos diferentes valores que a variável pode assumir, com base em uma lista ordenada desses valores. Como a correlação de Spearman não utiliza o valor absoluto do número, e sim o valor da sua posição no conjunto ordenado, ela pode ser aplicada a baixos números amostrais, a valores derivados de variáveis qualitativas ordinais e a dados que não possuem distribuição normal. Dos indicadores utilizados no estudo, Enac e IDDc podem ser considerados ordinais. ${ }^{6}$ Além disso, nem todos os indicadores apresentaram distribuição normal. O teste $\mathrm{t}$ foi utilizado como estatística para a testagem da significância da correlação. Esse teste verifica o quanto da variação do dado pode ser atribuído à relação entre o par de indicadores. 
Quanto maior o t, menor a probabilidade (p) de que o par de indicadores não tenha relação. Dessa forma, um p que tende a zero demonstra alta relação entre os indicadores. Optou-se por avaliar as correlações em dois níveis de significância, $5 \%$ e $10 \%$, tendo em vista o caráter exploratório deste estudo e a natureza ordinal das variáveis de desempenho. Considerou-se importante explorar aquelas correlações que estiveram acima da significância de 5\%, mas abaixo de $10 \%$, com vistas a determinar quais pares de indicadores apresentaram correlações significativas com maior frequência nos níveis de análise adotados.

Para a representação gráfica dos grupos de similaridades encontradas entre as combinações estudadas foi aplicada a técnica de análise de agrupamentos, utilizando-se a Distância Euclidiana como medida métrica de similaridade e o método de Ward para a amalgamação. Ressalta-se que as técnicas aqui empregadas tiveram um intuito exploratório dos indicadores. Não se pretendeu comprovar relações estritas de causa e efeito entre os indicadores utilizados, como qualidade de ensino e desempenho dos estudantes, o que, aliado à natureza escalar e não normal dos dados, motivou a escolha da técnica mais simples de correlação de postos ao invés de regressão múltipla, que também poderia ser aplicável neste tipo de estudo.

\section{As relações encontradas entre os indicadores de qualidade e desempenho em Pedagogia}

A Tabela 1 mostra as correlações encontradas, que variaram de próximas a zero até 59,5\%, a maior correlação apresentada. Não foram encontradas correlações que possam ser consideradas fortes em termos qualitativos, ou seja, iguais a ou acima de 70\%. Esse padrão é esperado tendo em vista a natureza complexa dos indicadores, ordinais e proporcionais, além dos números amostrais trabalhados no estudo. Sabe-se que o exame de correlações com baixos números amostrais pode apresentar valores altos de correlação, porém sem significância, o contrário ocorrendo quando os números amostrais são maiores. Nestes, há tendência de correlações fracas acusarem significância. Por isso, é regra prática no exame de correlações observar a significância das correlações com baixo número amostral, mas também a força da correlação (e não somente a significância) quando lidamos com altos números amostrais. Dessa forma, é esperado que as correlações gerais calculadas a partir de todas as 472 IES do estudo apresentem mais significância do que aquelas calculadas para as combinações entre a organização acadêmica e a categoria administrativa das instituições. Essa condição torna relevante o resultado encontrado no estudo, visto que as combinações de menor número amostral (por exemplo, faculdades integradas privadas, com $\mathrm{n}=28$ ) apresentaram mais correlações significativas do que combinações com maior número amostral (por exemplo, universidades privadas, com $n=118$ ). Com isso, os resultados encontrados indicam que existiram diferenças nas relações entre os indicadores para as combinações avaliadas. Quanto ao fato de a maior 
parte das correlações observadas serem fracas ou moderadas, espera-se um padrão como este em relações complexas como as que aqui estão sendo discutidas, entre pressupostos indicadores de qualidade do ensino e o desempenho dos estudantes, que forçosamente implicam relações de múltiplas variáveis, além das aqui avaliadas.

Tabela 1 - Correlações de Spearman (em percentuais) de acordo com o Par de Indicadores Analisado dos Cursos de Pedagogia Selecionados do Enade de $2008^{(1)}$

\begin{tabular}{|c|c|c|c|c|c|c|c|c|}
\hline \multirow[b]{2}{*}{ Indicador ${ }^{(3)}$} & \multicolumn{8}{|c|}{ Organização Acadêmica-Categoria administrativa(2) } \\
\hline & $\begin{array}{l}\text { Geral } \\
(472)\end{array}$ & $\begin{array}{l}\text { UniFed } \\
\text { (54) }\end{array}$ & $\begin{array}{c}\text { UniEst } \\
(50)\end{array}$ & $\begin{array}{c}\text { UniPri } \\
\text { (118) }\end{array}$ & $\begin{array}{c}\text { FacPri } \\
\text { (111) }\end{array}$ & $\begin{array}{c}\text { CenPri } \\
\text { (62) }\end{array}$ & $\begin{array}{c}\text { IntPri } \\
\text { (28) }\end{array}$ & $\begin{array}{c}\text { InsPri } \\
\text { (37) }\end{array}$ \\
\hline Eq\&Enac & $-3,9^{\text {ns }}$ & $10,7^{\mathrm{ns}}$ & $29,2^{*}$ & $5,8^{\text {ns }}$ & $27,6^{*}$ & $-7,2^{\text {ns }}$ & $4,6^{\mathrm{ns}}$ & $24,8^{\text {ns }}$ \\
\hline PE\&Enac & $2,2^{\text {ns }}$ & $4,7^{\mathrm{ns}}$ & $17,0^{\text {ns }}$ & $3,8^{\text {ns }}$ & $10,9^{\text {ns }}$ & $4,1^{\mathrm{ns}}$ & $21,9^{\text {ns }}$ & $31,2^{\#}$ \\
\hline Ms\&Enac & $23,2^{*}$ & $4,8^{\mathrm{ns}}$ & $37,7^{*}$ & $15,8^{\#}$ & $18,4^{\#}$ & $6,1^{\text {ns }}$ & $45,3^{*}$ & $15,3^{\text {ns }}$ \\
\hline Dr\&Enac & $35,8^{*}$ & $24,7^{\#}$ & $38,8^{*}$ & $19,6^{*}$ & $18,8^{*}$ & $21,5^{\#}$ & $59,5^{*}$ & $27,4^{\mathrm{ns}}$ \\
\hline DI\&Enac & $15,0^{*}$ & $9,2^{\text {ns }}$ & $10,0^{\mathrm{ns}}$ & $-4,9^{\text {ns }}$ & $-9,0^{\text {ns }}$ & $-10,3^{\text {ns }}$ & $-11,1^{\mathrm{ns}}$ & $-20,5^{\mathrm{ns}}$ \\
\hline Eq\&IDDc & $0,8^{\text {ns }}$ & $10,8^{\text {ns }}$ & $34,9^{*}$ & $-4,1^{\mathrm{ns}}$ & $22,4^{*}$ & $-2,1^{\mathrm{ns}}$ & $8,6^{\mathrm{ns}}$ & $9,2^{\mathrm{ns}}$ \\
\hline PE\&IDDc & $3,5^{\mathrm{ns}}$ & $12,9^{\text {ns }}$ & $20,0^{\text {ns }}$ & $-1,1^{\mathrm{ns}}$ & $3,0^{\text {ns }}$ & $6,0^{\text {ns }}$ & $21,1^{\mathrm{ns}}$ & $21,1^{\mathrm{ns}}$ \\
\hline Ms\&IDDc & $13,9^{*}$ & $-12,1^{\mathrm{ns}}$ & $34,3^{*}$ & $3,7^{\mathrm{ns}}$ & $14,0^{\mathrm{ns}}$ & $0,6^{\mathrm{ns}}$ & $43,8^{*}$ & $16,1^{\mathrm{ns}}$ \\
\hline Dr\&IDDc & $24,0^{*}$ & $3,6^{\mathrm{ns}}$ & $35,2^{*}$ & $14,9^{\text {ns }}$ & $16,7^{\#}$ & $18,8^{\text {ns }}$ & $45,5^{*}$ & $23,8^{\text {ns }}$ \\
\hline DI\&IDDc & $5,3^{\mathrm{ns}}$ & $8,8^{\text {ns }}$ & $-5,3^{\mathrm{ns}}$ & $-8,7^{\mathrm{ns}}$ & $-7,0^{\mathrm{ns}}$ & $-16,8^{\mathrm{ns}}$ & $10,7^{\mathrm{ns}}$ & $-19,1^{\mathrm{ns}}$ \\
\hline
\end{tabular}

Fonte: Elaboração própria.

Notas: (1): o símbolo * denota correlação significativa a $5 \%(p<0,05)$; \# a $10 \%(p<0,10)$ e ns indica não significância $(p>0,10)$.

(2): UniFed: Universidade federal; UniEst: Universidade estadual; UniPri: Universidade privada; FacPri: Faculdade Privada; CenPri: Centro Universitário Privado; IntPri: Faculdade Integrada Privada; InsPri: Instituto ou Escola Superior Privada. Números amostrais em parênteses.

(3): O símbolo " $\&$ " foi utilizado para identificar os pares de variáveis que foram correlacionados, quais sejam: Eq: Percentual de respostas satisfatórias relativas ao equipamento; PE: Percentual de respostas satisfatórias em relação aos planos de ensino; Dr: Percentual de Doutores, Ms: Percentual de Mestres; DI: Percentual de docentes parcial/integral, Enadec: valor do Enade contínuo; IDDc: valor do IDD contínuo.

${ }^{7}$ Significância refere-se à probabilidade de que as correlações possam ter sido encontradas aleatoriamente na amostra estudada. Correlações com valor de probabilidade (p) abaixo de $5 \%$ são muito significativas, enquanto aquelas com valor de probabilidade acima de $5 \%$ e abaixo de $10 \%$ têm menor significância que as primeiras.
Com relação aos pares de indicadores analisados, os percentuais de mestres e de doutores foram os indicadores com as maiores correlações com os dois indicadores de desempenho utilizados: Enade contínuo e IDD contínuo. Em geral, ainda foi observada correlação significativa entre o percentual de docentes em tempo parcial/integral e o Enade contínuo. Quando observadas as combinações entre organização acadêmica e categoria administrativa, percebe-se que para a maior parte delas o percentual de doutores apresentou correlação significativa com o Enade contínuo, seja a $5 \%$ ou a $10 \%$ de significância ${ }^{7}$, exceto nas IES pertencentes aos institutos ou escolas superiores privados. Porém, mesmo essa combinação apresentou correlação próxima a 10\% $(\mathrm{p}=0,1012)$, ou seja, à medida que os percentuais 
dos indicadores aumentaram, aumentou o desempenho representado pelo Enade contínuo ou IDD contínuo. Em seguida, o par entre o percentual de mestres e o Enade contínuo foi aquele com maior número de correlações significativas, quatro entre as sete combinações analisadas, fato observado também para o IDD contínuo. Em seguida aparece o par percentual de respostas satisfatórias em relação aos equipamentos, com duas correlações significativas com o Enade contínuo e duas com o IDD contínuo. Os indicadores relativos ao regime de trabalho e aos planos de ensino foram aqueles que quase não apresentaram correlações significativas, ou seja, caracterizou-se a ausência de relação entre esses indicadores e o Enade contínuo ou o IDD contínuo. Exceção é feita à correlação de $15 \%$ em nível geral para as IES entre o Enade contínuo e o percentual de docentes de tempo parcial/integral e a correlação de 31,2\% entre Enade contínuo e percentual de respostas satisfatórias em relação aos planos de ensino, encontrada para os institutos e escolas de educação superior, significativa a $10 \%$.

Esse padrão entre os indicadores pode ser visto na Figura 1, que mostra os agrupamentos de pares de indicadores formados com base nas correlações independentemente de sua significância; nesta, é possível observar que três grupos de indicadores foram estabelecidos. Um primeiro, formado pelos indicadores de percentual de equipamentos e planos de ensino com o Enade contínuo e o IDD contínuo, com as correlações intermediárias; um segundo grupo dos indicadores de percentual de mestres e doutores com o Enade contínuo e o IDD contínuo, que apresentou as maiores correlações; e um terceiro grupo para o indicador percentual de dedicação parcial/integral, que apresentou as menores correlações.

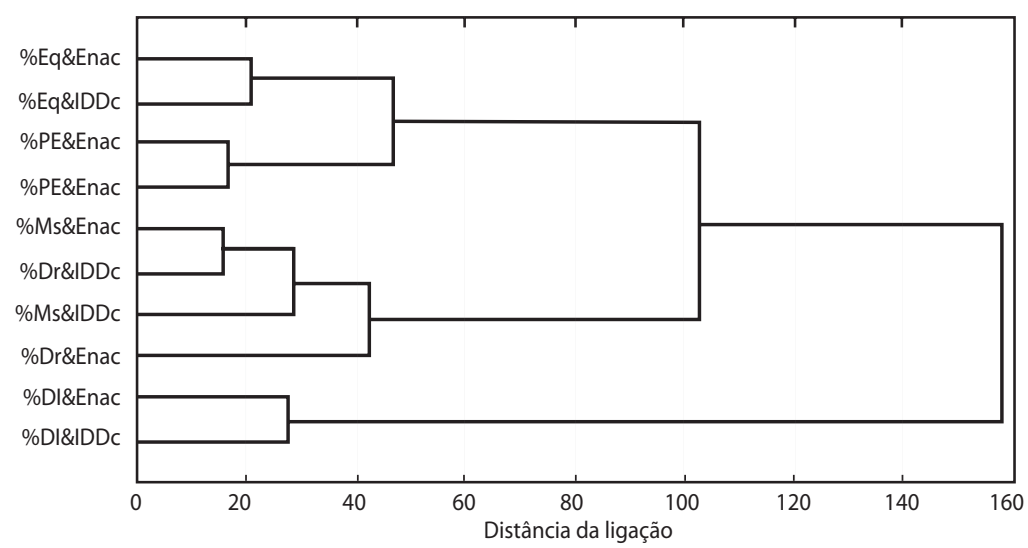

Figura 1 - Grupos de Pares dos Indicadores de Qualidade e de Desempenho Formados a partir das Correlações de Spearman para os Cursos de Pedagogia do Enade 2008

Fonte: Elaboração própria.

Notas: Indicadores de qualidade: Eq, PE, Ms, Dr e DI; indicadores de desempenho: Enac e IDDc. \%Eq e \%PE se referem ao percentual de respostas favoráveis aos equipamentos e planos de ensino; $\% \mathrm{Ms}$, \%Dr e \%DI se referem ao percentual de mestres, doutores e docentes em regime parcial ou integral, respectivamente. 
O exame das correlações para cada combinação de IES mostra os padrões de semelhança entre as organizações acadêmicas e categorias administrativas. A análise de agrupamentos das correlações encontradas, independentemente de sua significância, é mostrada na Figura 2.

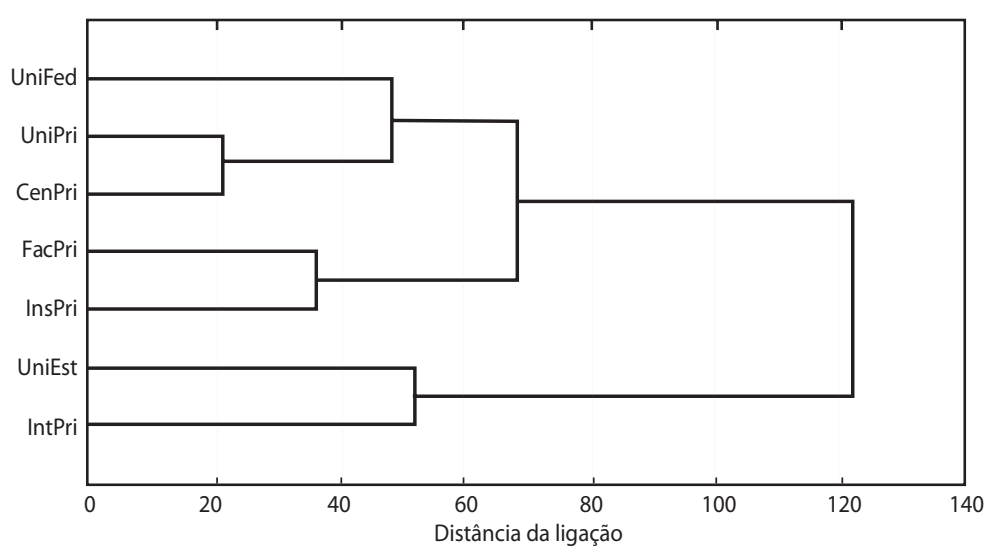

Figura 2 - Agrupamentos de Combinações de IES segundo sua Categoria Administrativa e Organização Acadêmica de acordo com o Valor Percentual das Correlações Encontradas entre os 10 Pares de Indicadores Avaliados

Fonte: Elaboração própria.

As universidades federais e privadas e os centros universitários privados apresentaram o menor número de correlações significativas, limitadas particularmente ao par percentual de doutores e Enade contínuo. As universidades federais apresentaram uma correlação maior $(24,7 \%)$ do que as privadas (19,6\%) ou os centros universitários (21,5\%). Esse fato, aliado à semelhança maior de correlações entre as duas últimas combinações de IES, foi o motivo de maior similaridade entre estas. O exame da Tabela 1 permite perceber que tanto as universidades privadas quanto os centros universitários apresentaram similaridades de correlações negativas, diferentemente do padrão apresentado para as universidades federais. As universidades privadas ainda mostraram correlação significativa de $15,8 \%(p<0,10)$ para o par percentual de mestres versus Enade contínuo. Outro grupo, próximo a esse primeiro, mostrou as faculdades privadas e os institutos superiores privados reunidos, também devido à similaridade das correlações positivas e negativas mútuas. Em contrapartida, as universidades estaduais e as faculdades integradas privadas apresentaram-se como um grupo à parte, com um padrão quase idêntico de altas correlações para os indicadores que relacionaram os percentuais de mestres e de doutores com o Enade contínuo e o IDD contínuo, conforme pode ser visto na Tabela 1. O par percentual de doutores e Enade contínuo mostrou correlação significativa de $38,8 \%$ e de $59,5 \%$, respectivamente, para as universidades estaduais e faculdades integradas privadas. Para o par percentual de mestres e Enade contínuo, as correlações foram de 37,7\% e 45,3\%, respectivamente. Esse padrão foi repetido para o IDD contínuo. A diferença entre essas duas 
combinações residiu na ausência de correlação significativa para o indicador percentual de equipamentos versus Enade contínuo e IDD contínuo nas faculdades integradas privadas.

\section{Considerações finais}

O exame das correlações entre os indicadores de qualidade de ensino e desempenho de estudantes dos cursos de Pedagogia que prestaram o Enade em 2008, realizado neste estudo, mostrou que as maiores e mais significativas correlações ocorreram entre os percentuais de doutores e os percentuais de mestres e o Enade contínuo e o IDD contínuo. Essas relações mostraram-se mais fortes nas universidades estaduais e nas faculdades integradas privadas, duas combinações de categoria administrativa e organização acadêmica que apresentaram o maior número de correlações significativas entre todos os pares de indicadores analisados. O indicador percentual de doutores foi aquele que apresentou as maiores e mais significativas correlações para todas as combinações avaliadas, à exceção dos institutos e das escolas privadas e, em menor grau, dos centros universitários privados. Esses resultados corroboram a ideia de que a titulação do corpo docente é um requisito que influencia na qualidade do ensino, além de mostrar que o Enade contínuo e o IDD contínuo possibilitaram evidenciar essa relação com a titulação para os cursos de Pedagogia.

Os percentuais de respostas satisfatórias quanto a equipamentos apresentaram fracas correlações para quase todas as combinações, exceto para as universidades estaduais e faculdades privadas; nestas, o indicador foi correlacionado significativamente com o Enade contínuo e o IDD contínuo. É interessante notar que esse indicador apresentou correlações quase nulas (3,9\% negativa com o Enade contínuo e 0,8\% com o IDD contínuo) para os cursos de Pedagogia vistos como um todo, mas uma correlação moderada (34,9\%) com o IDD contínuo para as universidades estaduais. Poderiam ser apontadas diferenças entre a práxis dos cursos de Pedagogia das universidades estaduais em face das federais ou privadas? Ou trata-se de uma questão interpretativa em relação ao questionamento realizado no questionário socioeconômico: "Aulas práticas: os equipamentos disponíveis são suficientes para todos os alunos?". Tratando-se da área de Pedagogia, é possível existirem interpretações distintas para a disponibilidade de equipamentos? Em termos gerais, os resultados apontam para uma necessidade de revisão desse indicador como insumo ao Conceito Preliminar de Curso (CPC).

Os percentuais de respostas satisfatórias em relação aos planos de ensino apresentaram somente uma correlação de 31,2\% significativa a $10 \%$ na categoria dos institutos e escolas de ensino superior, ou seja, somente nessa categoria, à medida que o percentual de resposta positiva em relação aos planos de ensino aumentou, também aumentou o desempenho representado pelo Enade contínuo. Ao que parece, para os cursos de Pedagogia, o questionamento "Os planos de ensino contêm todos 
os seguintes aspectos: objetivos; procedimentos de ensino e avaliação; conteúdos e bibliografia da disciplina?" não se configura em indicador adequado para ser relacionado com o desempenho discente. Percebe-se que o questionamento não exige do aluno respondente uma avaliação da qualidade do planejamento oferecido, mas sim da completude dos elementos indispensáveis, o que de forma alguma assegura qualidade no ensino-aprendizagem. Há grande diferença entre se apropriar da estrutura de elaboração de um plano de ensino e tornar esse plano um instrumento efetivo de aprendizagem. É provável que uma inadequação quanto à completude da estrutura leve a uma inadequação quanto ao processo de aprendizagem, e pode-se argumentar que nos institutos e nas escolas superiores esse fato ocorra, relacionando-se com o desempenho de seus estudantes. Mas, uma vez apropriada a "formatação" do plano, nada garante sua utilização como instrumento efetivo, e isso pode ter ocorrido nas demais combinações avaliadas. Conclui-se que esse indicador não é apropriado, para os cursos de Pedagogia, como insumo para o Conceito Preliminar de Curso.

O percentual de dedicação parcial/integral foi o indicador que mostrou as menores correlações em toda a análise realizada. Em nenhuma combinação de categoria administrativa e organização acadêmica foi possível obter correlações significativas, embora tenha ocorrido em nível geral uma correlação significativa de 15\% com o Enade contínuo. Esse foi o único indicador a mostrar várias correlações negativas, com destaque para as correlações de -20,5\% com o Enade contínuo e -19,1\% com o IDD contínuo para os institutos e as escolas privadas. A indicação é que, para a área de Pedagogia, a dedicação parcial/integral do docente à instituição não parece influenciar o desempenho. O exame da distribuição da carga horária docente entre graduação e pós-graduação seria obviamente o próximo passo para investigar essa ausência de relação nas universidades, pois nestas é frequente o deslocamento das atividades da graduação para a pós-graduação nos docentes de tempo parcial/integral, independente de sua categoria administrativa. Da forma como é coletado no Censo da Educação Superior, esse indicador não se configurou em insumo relevante para o conceito preliminar dos cursos de Pedagogia.

Resumem-se aqui as principais conclusões deste estudo:

- A titulação do corpo docente (mestres e doutores) foi o indicador que mais se relacionou com o desempenho dos estudantes de Pedagogia, tanto pelo Enade contínuo quanto pelo IDD, mostrando-se significativo para a maior parte das combinações entre organização acadêmica e categoria administrativa.

- O indicador que trata da infraestrutura não se mostrou relevante para a maioria das combinações entre organização acadêmica e categoria administrativa, com exceção das universidades estaduais.

- O indicador que trata dos planos de ensino não se mostrou relevante na relação com o desempenho discente.

- O indicador que trata da dedicação parcial/integral do docente à instituição não pareceu influenciar o desempenho. 
- A força das relações entre os indicadores de qualidade e desempenho foi dependente da combinação entre organização acadêmica e categoria administrativa. Devido a isso, a construção do CPC poderia considerar as diferenças existentes entre os tipos distintos de IES.

Entende-se que as relações entre essas variáveis não podem ser examinadas isoladamente. São muitos os fatores, tais como as condições sociais, culturais, econômicas, de infraestrutura e de gestão educacional, que deveriam fazer parte das análises propostas para a construção efetiva de uma prática avaliativa, de forma a alcançar a intenção do Sinaes exposta no início deste estudo, qual seja, a de dispor de um conjunto amplo e diverso de indicadores de avaliação para a qualidade institucional, e assim respeitar a diversidade do sistema de educação superior do Brasil. A observação das diferenças entre as categorias administrativas e organizações acadêmicas expostas neste estudo dá dimensão ao desafio que é respeitar a diversidade de nosso sistema de educação superior. Apesar disso, as relações encontradas permitem concluir que os indicadores do Enade e IDD têm cumprido sua função. A ressalva é feita quanto a seu uso predominante. Concordamos com Bordas e colaboradores (2008, p. 709) quando dizem:

Assim, para além dos dados quantificáveis, daquilo que pode ser aferido, medido, as políticas de avaliação da educação superior precisam penetrar nos significados produzidos no interior de cada instituição universitária, nas suas finalidades e "vocações" específicas, nos seus programas e planos de ação, na sua cultura, na dinâmica das relações que nela se estabelecem, nas suas contradições e conflitos, em seus consensos possíveis, na multiplicidade de vozes que desejam ser ouvidas, no intrincado tecido que constitui a comunidade acadêmica e científica. Respeitados esses princípios, faz sentido avaliar os desempenhos dos estudantes e das instituições formadoras. Faz sentido, portanto, considerá-la como instrumento de articulação de saberes e de comunidades de aprendizagens, num estímulo à mútua cooperação e às práticas formativas solidárias.

Para tanto, é necessário que as demais modalidades do Sinaes tenham papel tão relevante quanto o Enade no sistema de avaliação, notadamente a Avalies, que por sua natureza autorregulatória tem condições de realizar o descrito por Bordas e colaboradores.

Especificamente em relação ao indicador CPC, algumas possibilidades podem ser exploradas. A revisão das questões existentes no questionário socioeconômico do Enade parece ser a tarefa mais urgente. Uma composição multidimensional de determinadas questões pode ser uma alternativa viável ao uso das duas questões que atualmente servem como insumo ao CPC. Outra possibilidade, complexa, mas que respeitaria a heterogeneidade das organizações acadêmicas, seria a construção de CPCs específicos para cada uma destas. Dessa forma, o percentual de docentes em tempo parcial/integral poderia ser computado diferenciando-se graduação e pósgraduação. Os relatórios elaborados para o Avalies, o segundo pilar em que se baseia o Sinaes, poderiam servir de fonte de pesquisa para novos 
indicadores. É fato que a atual orientação do Inep para o relatório, que não propõe em seu núcleo comum uma proposta de indicadores comuns para as IES, impede o uso abrangente dos relatórios de autoavaliação. Por outro lado, seria inegável a melhoria na diversidade de indicadores de avaliação caso aspectos como rendimento acadêmico, formação continuada docente e avaliação institucional pudessem, qualitativa e quantitativamente, ser contemplados para a composição de um conceito de curso mais próximo à realidade complexa de uma instituição educacional.

Sem dúvida, para que essas possibilidades de mudança possam ser efetivadas seguramente, as questões examinadas neste estudo necessitam ser ampliadas para as demais áreas de concentração envolvidas no Enade. Respostas a questões como "Há diferenças nas relações quando examinadas grandes áreas de conhecimento?", "Que áreas apresentam padrões similares de relações?", "As áreas tecnológicas formam um grupo homogêneo e à parte de outros grupos, como as licenciaturas e os bacharelados?" poderão fornecer subsídios para uma tomada de decisão mais confiável e consensual com relação às mudanças necessárias no nosso sistema nacional de avaliação, de forma a garantir, da melhor maneira possível, os princípios nele estabelecidos e enfrentar os desafios a que ele se propôs, que não podem ser vistos como um encargo do órgão avaliador, mas de todas as IES brasileiras.

\section{Referências bibliográficas}

BITTENCOURT, H. R.; CASARTELLI, A. O.; RODRIGUES, A. C. M. Sobre o Índice Geral de Cursos (IGC). Avaliação: Revista de Avaliação da Educação Superior, Sorocaba, SP, v. 14, n. 3, p. 667-682, nov. 2009.

BORDAS, M. C.; MARQUES DE ALMEIDA, A. M. F. P.; DALBEN, A. I. L. F; RAMALHO, B. L.; FREITAS, H. L.; CAVALCANTE, L. I. P.; BITTAR, M. O olhar da comissão assessora de avaliação sobre o Enade da área de Pedagogia - 2005. Avaliação: Revista de Avaliação da Educação Superior, Sorocaba, SP, v. 13, n. 3, p. 681-712, nov. 2008.

BRASIL. Decreto $n^{\circ}$ 3.860, de 9 de julho de 2001. Dispõe sobre a organização do ensino superior, a avaliação de cursos e instituições, e dá outras providências. Diário Oficial da União, 10 jul. 2001. Seção 1 Eletrônico, p. 2. Disponível em: <http://www2.camara.gov.br/legin/fed/ decret/2001/decreto-3860-9-julho-2001-342382-publicacaooriginal-1-pe. html>. Acesso em: 28 fev. 2012.

BRASIL. Instituto Nacional de Estudos e Pesquisas Educacionais Anísio Teixeira (Inep). Nota técnica nº 029, de 15 de outubro de 2012. 
Disponível em: <http://download.inep.gov.br/educacao_superior/ ENADE/notas_tecnicas/2011/nota_tecnica_indicadores_2011_2.pdf $>$.

BRASIL. Lei no 10.861, de 14 de abril de 2004. Institui o Sistema Nacional de Avaliação da Educação Superior (Sinaes), e dá outras providências. Diário Oficial da União, Brasília, DF, 15 abr. 2004. Seção 1, p. 3-4.

BRASIL. Ministério da Educação (MEC). Comissão Nacional de Avaliação. Avaliação das universidades brasileiras: uma proposta nacional: documento básico. Brasília, DF, nov. 1993.

BRASIL. Ministério da Educação (MEC). Portaria Normativa MEC $\mathrm{n}^{\circ} 4$, de 5 de agosto de 2008. Regulamenta a aplicação do conceito preliminar de cursos superiores, para fins dos processos de renovação de reconhecimento respectivos, no âmbito do ciclo avaliativo do Sinaes instaurado pela Portaria Normativa $n^{\circ}$ 1, de 2007. Diário Oficial da União, Brasília, DF, 6 ago. 2008. Seção 1, p. 19.

BRASIL. Ministério da Educação (MEC). Secretaria de Educação Superior (SESu). Programa de Avaliação Institucional das Universidades Brasileiras. Brasília, DF: SESu, 1994.

DIAS SOBRINHO, J. Avaliação como instrumento de formação cidadã e do desenvolvimento da sociedade democrática: por uma éticoepistemologia da avaliação. Educação Superior em Debate, Brasília, DF, v. 1, p. 15-38, 2005.

EMBIRUÇU, M.; FONTES, C.; ALMEIDA, L. Um indicador para a avaliação do desempenho docente em Instituições de Ensino Superior. Ensaio: Avaliação e Políticas Públicas em Educação, Rio de Janeiro, v. 18, n. 69, p. 795-820, out./dez. 2010.

GURGEL, C. R. Análise do Exame Nacional de Desempenho dos Estudantes após o primeiro ciclo avaliativo das áreas de agrárias, saúde e serviço social do Estado do Piauí. Ensaio: Avaliação e Políticas Públicas em Educação, Rio de Janeiro, v. 18, n. 66, p. 85-104, jan./mar. 2010.

PEIXOTO, M. C. L. Avaliação institucional externa no Sinaes: considerações sobre a prática recente. Avaliação: Revista de Avaliação da Educação Superior, Sorocaba, SP, v. 16, n. 1, p. 11-36, mar. 2011.

RISTOFF, D. I. O Sinaes e seus desafios. Avaliação: Revista de Avaliação da Educação Superior, Sorocaba, SP, v. 9, n. 1, p. 179-183, mar. 2004. 
ROTHEN, J. C.; BARREYRO, G. B. Avaliação da educação superior no segundo governo Lula: "Provão II" ou a reedição de velhas práticas? Educação \& Sociedade, v. 32, n. 114, p. 21-38, jan./mar. 2011.

VENDRAMINI, C. M. M. Avaliação multidimensional de desempenho do estudante. Avaliação: Revista de Avaliação da Educação Superior, Sorocaba, SP, v. 10, n. 3, p. 27-40, set. 2005.

VIANNA, H. M. Avaliação educacional: teoria, planejamento, modelos. São Paulo: Ibrasa, 2000. 192 p.

WEBER, S. Avaliação e regulação da educação superior: conquistas e impasses. Educação \& Sociedade, Campinas, SP, v. 31, n. 113, p. 12471269, out./dez. 2010.

Leo Lynce Valle de Lacerda, doutorando em Educação (Políticas Públicas) pela Universidade do Vale do Itajaí (Univali), é professor dessa instituição e atua no programa de avaliação e na administração acadêmica da universidade, Itajaí, Santa Catarina, Brasil.

leolynce@univali.br

Cássia Ferri, doutora em Educação (Currículo) pela Pontifícia Universidade Católica de São Paulo (PUC-SP), é docente e pesquisadora do Programa de Mestrado em Educação da Universidade do Vale do Itajaí (Univali), Itajaí, Santa Catarina, Brasil.

cassia@univali.br

Recebido em 2 de março de 2014.

Solicitação de correções em 18 de novembro de 2014.

Aprovado em 20 de novembro de 2014. 